\title{
Controlled Drought Affects Morphology and Anatomy of Salvia splendens
}

\author{
Stephanie E. Burnett ${ }^{1}$, Svoboda V. Pennisi, Paul A. Thomas, and Marc W. van Iersel \\ Department of Horticulture, University of Georgia, 1111 Miller Hall Plant Sciences Building, Athens, \\ GA 30602
}

\begin{abstract}
AdDitional INDEX WORDs. polyethylene glycol, plug, water relations, bedding plant
Abstract. Polyethylene glycol 8000 (PEG-8000) was applied to a soilless growing medium at the concentrations of 0 , $15,20,30,42$, or $50 \mathrm{~g} \cdot \mathrm{L}^{-1}$ to impose controlled drought. Salvia (Salvia splendens $\mathbf{F}$. Sellow. ex Roem \& Shult.) seeds were planted in the growing medium to determine if controlled drought affects morphology and anatomy of salvia. Polyethylene glycol decreased emergence percentage and delayed emergence up to 5 days. Stem elongation of salvia treated with the five lowest concentrations was reduced up to $35 \%$ ( 21 days after seeding), and salvia were a maximum of $53 \%$ shorter and the canopy was $20 \%$ more narrow compared to nontreated seedlings $\mathbf{7 0}$ days after seeding. These morphological changes were attributed to PEG-8000 mediated reduction in leaf water potential $\left(\Psi_{\mathrm{w}}\right)$. The growing medium $\Psi_{w}$ ranged from -0.29 to $-0.85 \mathrm{MPa}$ in PEG-8000 treated plants, and plant height was positively correlated with $\Psi_{w} 21$ days after seeding. Stem diameter of PEG-treated seedlings was reduced up to 0.4 mm mainly due to reductions in vascular cross-sectional area. Xylem cross-sectional area decreased more than stem and phloem cross-sectional area. Polyethylene glycol 8000 reduced vessel element number, but not diameter.
\end{abstract}

Drought is commonly used to reduce elongation (or growth) of greenhouse ornamentals. Plants grown in substrates that have a low water potential $\left(\Psi_{\mathrm{w}}\right)$ typically have low leaf $\Psi_{\mathrm{w}}$ and turgor potential $\left(\Psi_{\mathrm{p}}\right)$. Turgor potential, in excess of the minimum "yield" threshold, is the driving force for cell elongation (Carpita and McCann, 2000; Cosgrove, 1997; Frensch, 1997; van Volkenburgh 1999). Thus, commercial greenhouse growers use drought stress to slow elongation of plants such as vegetable transplants (Latimer, 1992; Latimer and Severson, 1997).

The disadvantage of using drought to reduce ornamental seedling growth is that it can cause damage, including leaf abscission and reduced germination (Mohr and Schopfer, 1995). Even minor damage, such as marginal leaf scorching, would decrease seedling quality. Further complicating the matter, seedlings are grown in small substrate volumes $(\approx 8 \mathrm{~mL}$ for trays with 288 seedlings) that dry out quickly between irrigations. It would be desirable for growers to have a method of controlling drought stress so that seedlings are shorter, but not damaged.

Osmotic compounds, such as polyethylene glycol (PEG) can be used to impose controlled drought. Polyethylene glycol forms hydrogen bonds with water and decreases the matric potential of substrates (Kjellander and Florin, 1981; Steuter et al., 1981). Postgermination PEG drenches reduced elongation of salvia and french marigold (Tagetes patula L.) (Burnett et al., 2004). Other plants that exhibited less shoot or root growth when exposed to PEG compounds of varying molecular weight include rice (Oryza sativa $\mathrm{L}$.), monterey pine [Pinus radiata $\mathrm{D}$. Don $(P$. insignis Dougl. ex Loud.)], maize (Zea mays L.), and sorghum [Sorghum bicolor (L.) Moench (S. vulgare Pers.)] (Choi et al., 2000; Gill et al., 2001; Lawlor, 1970; Zou et al., 2000).

Annual salvia was chosen as the model crop candidate for height control using controlled drought for several reasons. Firstly,

Received for publication 17 Dec. 2004. Accepted for publication 1 Mar. 2005. Based on part of a dissertation in partial fulfillment of the requirements for a $\mathrm{PhD}$ degree at the Univ. of Georgia. We thank Carrie Radcliffe and Matt Hawkins for technical assistance and Hugh Earl, Peter Hartel, and Hazel Wetzstein for their helpful comments on an early draft of this manuscript.

'To whom reprint requests should be addressed. E-mail: seburnett@adelphia. net salvia grows rapidly, and chemical growth retardants are usually recommended for commercial greenhouse production (Nau, 1998). Secondly, previous research reported that drought-stressed salvia (leaf $\Psi_{\mathrm{w}}=-1.1$ to $-1.4 \mathrm{MPa}$ ) were shorter and more compact than nonstressed salvia (Eakes et al., 1991).

Morphological changes such as reduced stem and leaf elongation frequently reflect anatomical changes. It would be of interest to correlate morphological information with anatomical data, in order to describe the manifested macroscopic changes. For this reason, the two objectives of this experiment were to confirm that PEG reduces $\Psi_{\mathrm{w}}, \Psi_{\mathrm{p}}$, solute potential $\left(\Psi_{\mathrm{s}}\right)$, and shoot elongation of a commercially important summer annual bedding plant, salvia, and to determine the mechanism by which plant morphology is modified. This research builds upon the foundation of previous research to determine whether drought stress may be used to control elongation of commercial seedlings (Eakes et al., 1991). In addition, previous research did not determine how salvia anatomy was affected by reduced elongation.

\section{Materials and Methods}

Polyethylene glycol 8000 (Fisher Scientific, Fairlawn, N.J.) was mixed with water and added to a commercial peat-based growing medium specifically formulated for germinating seedlings [a mixture of sphagnum peat, perlite, and vermiculite (Germinating mix; Fafard, Anderson, S.C.) resulting in the following concentrations in the growing medium: $0,15,20,30,42$, and $50 \mathrm{~g} \cdot \mathrm{L}^{-1}$. Each PEG-8000 and growing medium combination was shaken vigorously in a large plastic container for $10 \mathrm{~min}$ to produce a homogenous mix. Treated growing medium was placed in $6 \times 6$ cell sections cut from 288-trays (cell volume $=8.5 \mathrm{~mL}$ ). Each $6 \times 6$ section was one experimental unit. Substrate $\Psi_{\mathrm{w}}$ of three samples from each treatment was measured using a vapor pressure osmometer (model 5520 Vapro; Wescor, Logan, Utah). The volumetric water content of the growing medium during these measurements was approximately $29 \%$, which was the target water content for the duration of the experiment.

Two salvia 'Bonfire' seeds (Ball Seed Co., West Chicago, Ill.) were planted in each of the 36 cells in an experimental unit on 6 June 2003. Salvia seeds were grown until emergence in a growth 
chamber (modelE-15; Conviron, Winnipeg, Canada) (light levels $\approx 300 \mu \mathrm{mol} \cdot \mathrm{m}^{-2} \cdot \mathrm{s}^{-1}$, temperature $\approx 24{ }^{\circ} \mathrm{C}$ ). While in the growth chamber, plants were misted overhead as needed to maintain a constant volumetric water content $(29 \% \pm 3 \%)$. Fourteen days after seeding, plants were transferred to a mist bench in a glass greenhouse (average temperature $=25 \pm 4.4^{\circ} \mathrm{C}$ ) and irrigated $20 \mathrm{~s}$ every $20 \mathrm{~min}$ from $0600 \mathrm{until} 1800 \mathrm{HR} 15 \mathrm{~d}$ after seeding. The mist timing was changed to $20 \mathrm{~s}$ every $30 \mathrm{~min}$ from 0600 until 1800 HR $19 \mathrm{~d}$ after seeding, to maintain appropriate irrigation levels. The smaller seedling was removed from cells containing more than one plant $27 \mathrm{~d}$ after seeding. All seedlings were hand-misted overhead twice weekly for $20 \mathrm{~s}$ with a $20 \mathrm{~N}-8.7 \mathrm{P}-16.6 \mathrm{~K}$ fertilizer (20-20-20 General Purpose; Scotts Co., Marysville, Ohio) solution with a $\mathrm{N}$ concentration of $200 \mathrm{mg} \cdot \mathrm{L}^{-1}$, beginning when the first true leaves were visible ( $23 \mathrm{~d}$ after seeding). When plugs were fertilized, they were removed from the mist bench.

Experimental unit weight was recorded twice daily throughout the experiment and irrigation was adjusted as necessary to maintain constant water contents $(29 \% \pm 3 \%)$. Since PEG is water soluble, this also prevented leaching which would have resulted in loss of PEG and thus change treatment levels. Empty tray weights were noted at the beginning of the experiment. After emergence, one representative seedling from the outermost row was harvested bi-weekly. The weight of this seedling was multiplied by the number of plants in each tray to account for changes in plant weight throughout the experiment. Each tray contained $\approx 307$ $\mathrm{mL}$ of growing medium, and the same volume of excess treated growing mix was dried in a drying oven at approximately $80^{\circ} \mathrm{C}$. The amount of water in each tray was calculated by subtracting the tray, seedling, and dry growing medium weight from the experimental unit weight. The drying oven did not completely remove all the water bound to PEG-8000 from the growing medium. Thus, the estimated dry weight of the growing medium included some water, which was bound to the PEG-8000 at temperatures up to $80{ }^{\circ} \mathrm{C}$ and therefore not available for plant uptake.

Data collected include number of days to emergence (cotyledons perpendicular to hypocotyl) and emergence percentage. Plants in the outermost rows of the $6 \times 6$ cell sections were not measured to prevent edge effects. Height from the top of the growing medium and width between the widest two leaf tips was measured 21 and $70 \mathrm{~d}$ after seeding. At harvest (70 d after seeding) leaf area was measured using a leaf area meter (LI-3100; LICOR, Lincoln, Nebr.). Roots were washed to remove the growing medium, then the longest root length was recorded. Shoot (stems and leaves) and root tissues were dried in an oven at $80^{\circ} \mathrm{C}$ for at least $3 \mathrm{~d}$; then dry weights were measured. Compactness (leaf area/height at harvest) and stem density (stem dry weight/stem length) were calculated from these data. All living seedlings except those from the border were harvested for shoot data, but, for roots, only four representative plants were harvested.

Leaf WATER RELATIONS. Midday leaf $\Psi_{\mathrm{w}}\left[\Psi_{\mathrm{w}}=\Psi_{\mathrm{p}}+\Psi_{\mathrm{s}}\right]$ of the second acropetal pair of leaves from representative plants from three blocks was measured 21, 35, and $56 \mathrm{~d}$ after seeding using individually calibrated leaf-cutter thermocouple psychrometers (J.R.D. Merrill Specialty Equipment, Logan, Utah). Leaf samples enclosed in the psychrometer chambers were equilibrated in a water bath at $25^{\circ} \mathrm{C}$ for $4 \mathrm{~h}$ before measurement. Water potential of intact leaves was measured first using a microvoltmeter. Then, leaf samples were frozen to disrupt cell membranes and remove $\Psi_{\mathrm{p}}$. Samples were then re-equilibrated as described above and $\Psi_{\mathrm{s}}^{\mathrm{p}}$ was measured. Finally, $\Psi_{\mathrm{p}}$ was calculated by subtracting $\Psi_{\mathrm{s}}$ from $\Psi_{w}$.
Anatomy. At harvest, salvia leaves, stems, and roots from four representative blocks were fixed in Histochoice (Amresco, Solon, Ohio), an aldehyde-based fixative. Tissue from the second acropetal leaf, and the longest root and stem within $2 \mathrm{~mm}$ of the root-shoot junction were used. The tissue samples were dehydrated in an ascending ethyl alcohol series and embedded in Spurr's resin (Spurr, 1969) using standard histology protocols. Tissue samples were sectioned with a microtome (Leica, Wetzlar, Germany) to 3 $\mu \mathrm{m}$ thickness. Cross-sections were stained with $0.5 \%$ Toluidine Blue, mounted on poly-lysine coated slides, and examined with a light microscope (Zeiss, Thornwood, N.Y.). Stem diameter, xylem, phloem, and pith cross-sectional areas, and the average cross-sectional area of ten randomly selected xylem elements of plants treated with $0,15,30$, and $50 \mathrm{~g} \cdot \mathrm{L}^{-1}$ of PEG-8000 were measured. The xylem element number within $1 / 4$ of the stem cross-sectional area was counted. This number was multiplied by four to estimate the xylem element number within a crosssection. Stem cross-sectional area was calculated from the stem diameter. The cortex cross-sectional area and ratios of xylem to phloem cross sectional area, xylem to stem cross-sectional area, and phloem to stem cross-sectional area were calculated from these data. Root xylem and pith cross-sectional area and leaf, palisade, and spongy mesophyll thickness were measured. Micrographs were captured digitally under the same magnification. Diameters were calculated using Adobe Photoshop software (Adobe Systems, San Jose, Calif.) and micrometer measurements. Cross-sectional areas of xylem, phloem, and pith were measured by calculating the number of pixels in a grid with sides of known lengths (from the micrometer). Cross-sectional area was then calculated by dividing the pixels in a measured cross-sectional area by the number of pixels in an area of known dimensions.

The experimental design was a randomized complete block design with six blocks, and 16 subsamples/treatment. For root harvest data, there were four subsamples/treatment. Three blocks were measured for water relations data, and four blocks were measured for anatomical data. Data were analyzed using regression analysis (Proc GLM of SAS; SAS Inst., Cary, N.C.). Volumetric water contents were averaged over all measurements before analysis. Leaf water relations data were also further analyzed for correlations between $\Psi_{\mathrm{w}}, \Psi_{\mathrm{s}}$, and $\Psi_{\mathrm{p}}$ and seedling heights measured $21 \mathrm{~d}$ after seeding.

\section{Results and Discussion}

Salvia emergence percentages decreased with increasing PEG-8000 rates $(P$ value $=0.0020$; Burnett, 2004). Emergence percentage decreased from $81 \%$ in controls to $61 \%$ for seedlings treated with $50 \mathrm{~g} \cdot \mathrm{L}^{-1}$ of PEG-8000. Seed germination is typically reduced by water stress (Mohr and Schopfer, 1995). PEG-8000 reduces the matric potential of substrates (Steuter et al., 1981). In this experiment, the growing medium water potential decreased quadratically with increasing PEG-8000 concentration across a broad range $\left[-0.21\left(0 \mathrm{~g} \cdot \mathrm{L}^{-1}\right)\right.$ to $-0.85 \mathrm{MPa}\left(50 \mathrm{~g} \cdot \mathrm{L}^{-1}\right)$; Burnett et al., 2004]. PEG delayed emergence up to $5 \mathrm{~d}$ (from $11 \mathrm{~d}$ for control plants to $16 \mathrm{~d}$ for seeds exposed to $50 \mathrm{~g} \cdot \mathrm{L}^{-1}$; days to emergence $=11+3.32 \times 10^{-2} \mathrm{x}+1.36 \times 10^{-3} \mathrm{x}^{2}, R^{2}=0.75, P=0.0001, \mathrm{x}=$ PEG-8000 concentration in the growing medium). In previous experiments, PEG-8000 reduced and delayed germination of Tagetes patula (Burnett, 2004). All salvias emerged within $1 \mathrm{~d}$ of the normal germination time of 12 to $15 \mathrm{~d}$ (Nau, 1998).

Salvia stem elongation decreased quadratically with increasing PEG-8000 concentrations shortly after germination (21 d after seeding) and at harvest (Fig. 1 A and C). Seedlings treated with 50 

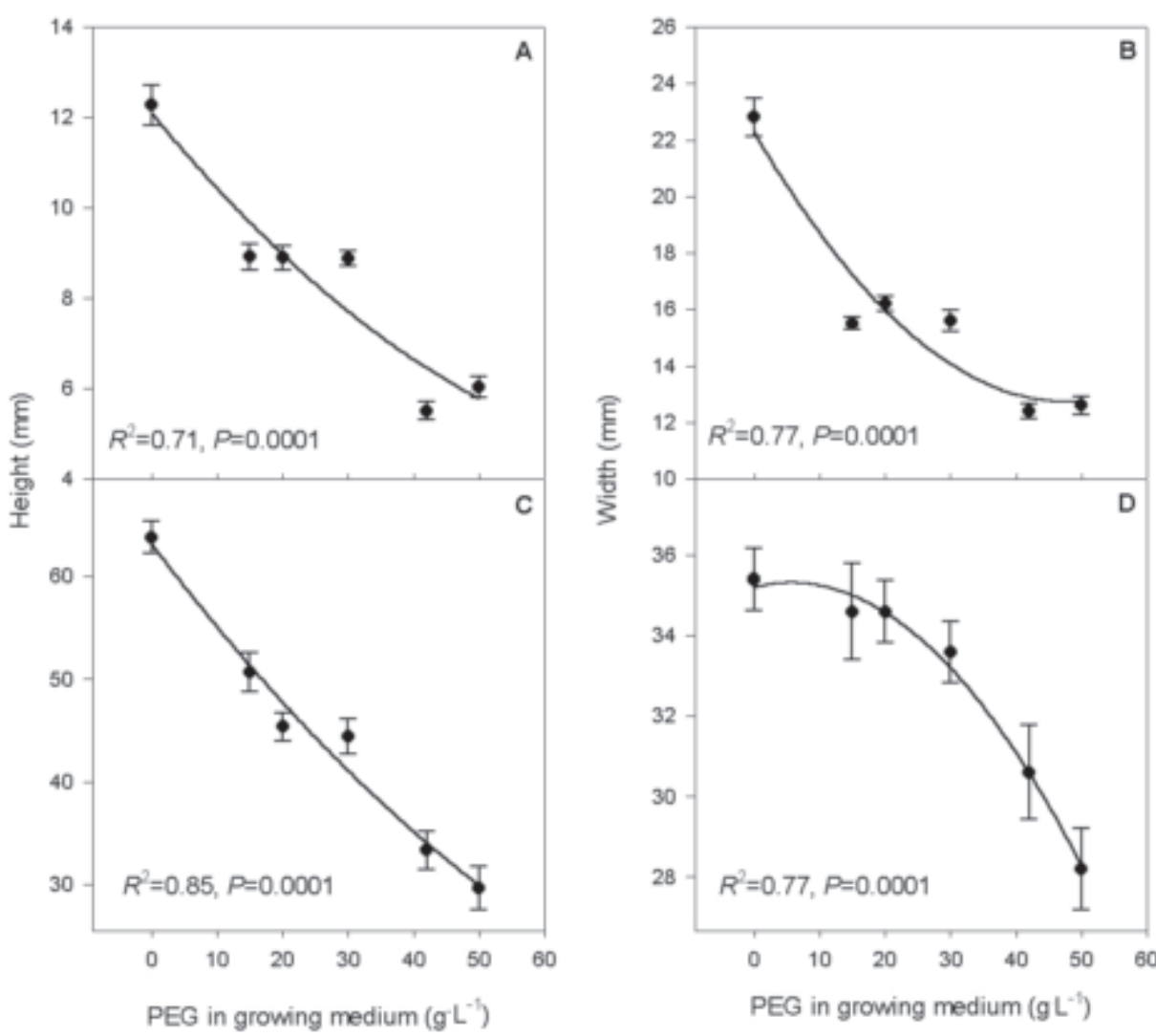

Fig. 1. The effects of PEG-8000 in the growing medium on height and width of salvia 21 and $70 \mathrm{~d}$ after seeding (harvest). Data points are the mean of six replications with bars representing standard error, and curves show significant quadratic effects. A: height $(21 \mathrm{~d}$ after seeding $)=17-0.28(\mathrm{PEG})+0.00175(\mathrm{PEG})^{2}$; B: width $(21 \mathrm{~d}$ after seeding $)=22-0.4(\mathrm{PEG})+0.00413(\mathrm{PEG})^{2} ; \mathrm{C}:$ height $(70 \mathrm{~d}$ after seeding $)=63-0.84(\mathrm{PEG})+0.00357(\mathrm{PEG})^{2}$; D: width $(70 \mathrm{~d}$ after seeding $)=35+0.0391(\mathrm{PEG})-0.00356(\mathrm{PEG})^{2}$.

$\mathrm{g} \cdot \mathrm{L}^{-1}$ of PEG-8000 were approximately half as tall as nontreated salvia $21 \mathrm{~d}$ after seeding and at harvest. However, seedlings treated with $50 \mathrm{~g} \cdot \mathrm{L}^{-1}$ of PEG-8000 had some foliar necrosis. Salvia treated with increasing concentrations of PEG-8000 were more narrow than nontreated salvia throughout the experiment (Fig. $1 \mathrm{~B}$ and D). Plants grown with the $50 \mathrm{~g} \cdot \mathrm{L}^{-1}$ of PEG-8000 were $53 \%$ shorter and the canopy was $20 \%$ narrower compared to controls at harvest, when seedlings were marketable. Since germination was delayed by PEG, the observed size differences may have been caused in part by differences in age. However, salvias of the same age treated with postgermination PEG-8000 drenches were up to $39 \%$ shorter and canopies were up to $24 \%$ more narrow at harvest compared to nontreated salvia (Burnett et al., 2004), indicating that PEG-induced differences in plant height are not solely due to differences in germination.

Compactness (leaf area per unit height), is another component of morphology, and PEG-treated salvia were more compact than nontreated plants (Fig. 2A). The most compact salvia were treated with $42 \mathrm{~g} \cdot \mathrm{L}^{-1}$ of PEG-8000, and they were $1.3 \mathrm{~cm}$ more compact than nontreated salvia. Height is more important than compactness since shorter, less compact seedlings would be cheaper to ship than taller, more compact seedlings. However, it is important for salvia to be shorter and more compact, since a short plant with few or very small leaves would be of low quality. Previously, Eakes et al. (1991) also reported that annual salvia exposed to episodic drought (moisture stress conditioned, with leaves reaching $\Psi_{\mathrm{w}}$ of -1.1 to $-1.4 \mathrm{MPa}$ on four separate occasions) were more compact than nonmoisture stress conditioned plants. In that experiment, leaf area was reduced less than shoot dry weight, but height was not measured (Eakes et al., 1991). In contrast, van Iersel and Nemali (2004) found that droughtstressed marigolds were shorter but less compact than nonstressed marigolds. PEG-treated marigolds were less compact than nontreated marigolds (Burnett et al., 2004). The relationship between height, compactness, and drought stress may be species specific. Salvia treated with PEG had less dense stems when treated increasing PEG concentrations. Stem density is another measure of compactness, and it was $0.5 \mathrm{~g} \cdot \mathrm{m}^{-1}$ for nontreated salvia compared to $0.24 \mathrm{~g} \cdot \mathrm{m}^{-1}$ for salvia treated with $50 \mathrm{~g} \cdot \mathrm{L}^{-1}$ of PEG-8000 (Fig. 2B). PEGtreated salvia probably had lower stem densities because they had thinner stems than nontreated salvia (Fig. 3A).

At harvest, salvia had smaller leaf areas with increasing rates of PEG-8000 (Fig. 4A). Salvia treated with $50 \mathrm{~g} \cdot \mathrm{L}^{-1}$ of PEG-8000 had 31\% less leaf area than control plants. Shoot dry weight also decreased quadratically for plants grown in more PEG-8000 (Fig. 4B). There was a large difference in shoot dry weight (40 $\mathrm{mg}$ ) between nontreated plants and salvia treated with the lowest concentration (15 $\left.\mathrm{g} \cdot \mathrm{L}^{-1}\right)$ of PEG-8000. PEG-8000 affected shoot dry weight more than leaf area (Fig. 4A-B). Osório et al. (1998) reported that leaf area and shoot dry weight of Eucalyptus globulus Labill. are equivalently affected by drought stress, while Eakes et al. (1991) found that shoot dry weight of annual salvia is affected by drought stress to a larger degree than leaf area. Similar to compactness, this relationship is probably species specific and deserves more attention in the future.

Root length and dry weight decreased linearly (dry weight) or quadratically (length) for seedlings treated with more PEG-8000 (Fig. 4B-C). Seedlings treated with $50 \mathrm{~g} \cdot \mathrm{L}^{-1}$ of PEG-8000 had roots that were $\approx 70 \mathrm{~mm}$ shorter and weighed $47 \%$ less than root of nontreated salvias (Fig. 4B-C). Similarly, drought-stressed pepper (Capsicum annuum, L.) seedlings had shorter and lighter roots than nonstressed peppers (Lescovar and Cantliffe, 1992; Watts et al., 1981). Roots are often less affected by drought stress than shoots, and drought-stressed plants often have higher root to shoot ratios than nonstressed plants (Hsiao and Jing, 1987; Sharp and Davies, 1979). However, root to shoot ratios were not significantly different in this experiment (data not shown).

LEAF WATER RELATIONS. Early in the experiment (21 d after seeding), leaf $\Psi_{\mathrm{w}}$ decreased quadratically from $-0.6 \mathrm{MPa}$ in control plants to a minimum of $-1.5 \mathrm{MPa}$ in seedlings treated with 42 $\mathrm{g} \cdot \mathrm{L}^{-1}$ of PEG-8000 (Fig. 5A). Osmotic potential and $\Psi_{\mathrm{p}}$ decreased linearly as PEG concentration in the growing medium increased (Fig. 5A). PEG reduced $\Psi_{\mathrm{s}}$ from -0.8 in nontreated salvia to -1.3 $\mathrm{MPa}$ in salvia treated with $42 \mathrm{~g} \cdot \mathrm{L}^{-1}$ of PEG-8000. Leaf $\Psi_{\mathrm{p}}$ of all PEG-treated seedlings was below zero $21 \mathrm{~d}$ after seeding. Since $\Psi_{\mathrm{p}}$ was negative and decreased with the addition of PEG-8000, cell elongation was probably reduced by PEG-8000, because $\Psi_{\mathrm{p}}$ is the driving force for cell elongation (Carpita and McCann, 


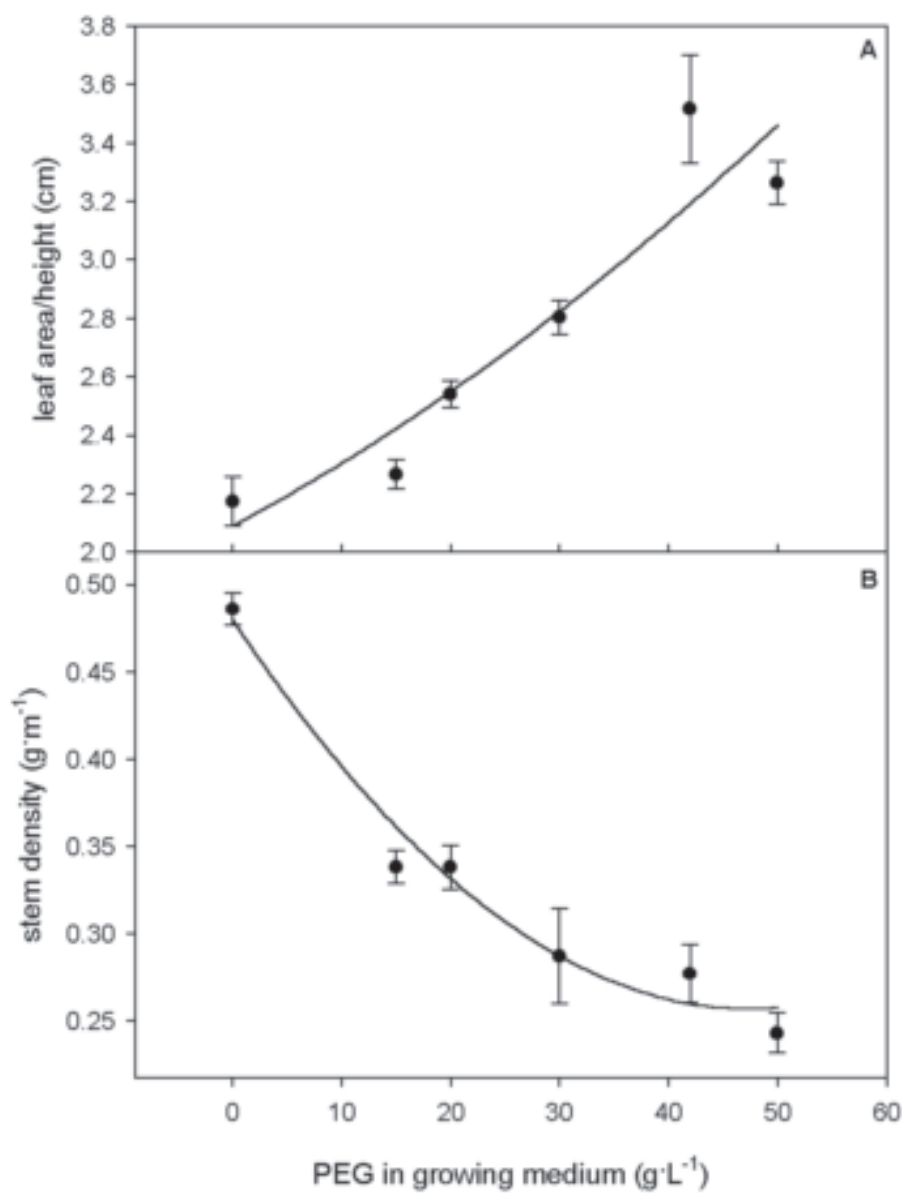

Fig. 2. The effects of PEG-8000 in the growing medium on compactness (A: leaf area/height at harvest) and stem density (B: stem dry weight/stem length at harvest) of salvia treated with PEG-8000. Salvia were harvested $70 \mathrm{~d}$ after seeding. Data points are the mean of six replications with bars representing standard error, and curves show significant quadratic effects. Compactness = $2.09+2.0 \times 10^{-2}(\mathrm{PEG})+1.49 \times 10^{-4}(\mathrm{PEG})^{2}, R^{2}=0.55, P=0.0011 ;$ stem density $=$ $0.48-9.39 \times 10^{-3}(\mathrm{PEG})+9.89 \times 10^{-5}(\mathrm{PEG})^{2}, R^{2}=0.64, P=0.0002$.

2000; Cosgrove, 1997; Frensch, 1997; van Volkenburgh 1999). At $21 \mathrm{~d}$ after seeding, height was positively correlated with leaf $\Psi_{\mathrm{w}}$ (height $=1.41+0.506 \Psi_{\mathrm{w}}, r^{2}=0.44, P=0.0060$ ).

The effect of PEG-8000 on leaf water relations was less 35 $\mathrm{d}$ after seeding than $21 \mathrm{~d}$ after seeding. At $35 \mathrm{~d}$ after seeding, $\Psi_{\mathrm{s}}$ decreased linearly as PEG-8000 rate increased (Fig. 5B). Nontreated salvia had a $\Psi_{\mathrm{s}}$ of $-1.02 \mathrm{MPa}, 35 \mathrm{~d}$ after seeding, and the lowest $\Psi_{\mathrm{s}}(-1.19 \mathrm{MPa})$ was measured in salvias treated with $50 \mathrm{~g} \cdot \mathrm{L}^{-1} \mathrm{PEG}-8000$. Polyethylene glycol 8000 did not significantly affect leaf $\Psi_{\mathrm{w}}$ or $\Psi_{\mathrm{p}} 35 \mathrm{~d}$ after seeding. At $56 \mathrm{~d}$ after seeding, $\Psi_{\mathrm{w}}$ and $\Psi_{\mathrm{p}}$ of seedlings decreased linearly with increasing PEG rate, but $\Psi_{\mathrm{s}}^{\mathrm{p}}$ was not affected by PEG-8000 treatments (Fig. 5C). For controls, $\Psi_{\mathrm{p}}$ was $0.33 \mathrm{MPa}$, and the lowest $\Psi_{\mathrm{p}}(-0.04 \mathrm{MPa})$ was measured in salvia treated with $42 \mathrm{~g} \cdot \mathrm{L}^{-1}$ of PEG-8000. Salvias treated with $30-50 \mathrm{~g} \cdot \mathrm{L}^{-1}$ of PEG-8000 all had $\Psi_{\mathrm{p}}$ close to or below zero. However, $\Psi_{\mathrm{p}}$ and $\Psi_{\mathrm{w}}$ of PEG-treated salvia was affected more $21 \mathrm{~d}$ after seeding than 35 and $56 \mathrm{~d}$ after seeding. Water potential could have been affected less by treatments at the later stages because PEG-8000 could have been washed out of the growing medium. Polyethylene glycol 8000 is highly water soluble, and, despite efforts to keep PEG-8000 in the growing medium, the possibility that PEG-8000 was washed out of the growing medium by irrigations cannot be eliminated.
Алатомy. Developing salvias have atypical stem anatomy with a continuous cylinder of xylem and phloem around the pith (Fig. 6A-D). Typical vascular systems in the stems of herbaceous dicotyledonous plants are arranged in vascular bundles, separated by interfascicular tissue (Esau, 1976). However, in the Lamiaceae family continuous xylem in stems is a characteristic trait of young plants (Metcalfe and Chalk, 1957).

Salvia stem diameter and xylem cross-sectional area decreased quadratically with increasing PEG concentrations (Figs. 3A-B and $6 \mathrm{~A}-\mathrm{D})$. Seedlings treated with $30 \mathrm{~g} \cdot \mathrm{L}^{-1}$ of PEG-8000 had the smallest stem diameter $(1.23 \mathrm{~mm})$ and xylem cross-sectional area $\left(0.22 \mathrm{~mm}^{2}\right)$ compared to nontreated seedlings which had a stem diameter of $1.62 \mathrm{~mm}$ and xylem cross-sectional area of $0.62 \mathrm{~mm}^{2}$. Stem diameter and xylem cross-sectional area are typically smaller in drought stressed plants. For example, grape (Vitis vinifera L.) grown at lower than optimal soil water potential $(-0.07 \mathrm{MPa})$ had reduced above ground shoot diameter and xylem cross-sectional area than grape grown at optimal soil water potential (-0.01 MPa) (Lovisolo and Schubert, 1998). Stem phloem cross-sectional area also decreased quadratically as seedlings were treated with more PEG-8000 (Figs. 3C and $6 \mathrm{~A}-\mathrm{D})$. Nontreated salvia had phloem cross-sectional areas of $\approx 0.23 \mathrm{~mm}^{2}$, while salvia treated with $50 \mathrm{~g} \cdot \mathrm{L}^{-1}$ of PEG-8000 had phloem cross-sectional areas of $\approx 0.15 \mathrm{~mm}^{2}$. This was probably not an adaptation to drought, rather it was likely due to the fact that seedlings grown in the presence of PEG-8000 were smaller than nontreated controls. Stem pith and cortex cross-sectional areas were not affected by PEG-8000 (data not shown). However, there appeared to be less pith in seedlings treated with 30 or $50 \mathrm{~g} \cdot \mathrm{L}^{-1}$ of PEG-8000, and, in some cases, pith was not readily discernible. The ratios of xylem to phloem and to stem cross-sectional area decreased with increasing PEG-8000 concentration (Table 1). The ratio of phloem to stem cross-sectional area was not affected by PEG-8000. In this experiment, xylem cross-sectional area decreased more in response to PEG than other tissues. For this reason, it is evident that the reduction of xylem tissue is one anatomical adaptation of salvia to controlled drought stress.

Plants reduce xylem cross-sectional area by reducing xylem element size, number, or both. According to Poiseuille's equation $\left[\mathrm{F}=\Delta \mathrm{P} \pi \mathrm{r}^{4} /(8 \eta \mathrm{l})\right.$, where $\mathrm{F}=$ flow rate, $\Delta \mathrm{P}=$ pressure difference, $r=$ radius, $\eta=$ viscosity, and $l=$ length of a tube], plants often increase vessel size when water is not limiting to increase the rate of water flow through xylem elements. It is theorized that vessel diameter is less at low soil water potentials to reduce the incidence of embolisms (Lo Gullo et al., 1995;Zimmerman, 1983). Vessel size was reduced in drought-stressed grapes (Lovisolo and Schubert, 1998). Sunflower (Helianthus annuus L.) and apple cactus [Cereus peruvianus L. (Mill.)] had smaller vessel diameter when grown at low soil water contents (Arnold and Mauseth, 1997; Penfound, 1931). For salvia, $15-50 \mathrm{~g} \cdot \mathrm{L}^{-1}$ of PEG-8000 did not significantly affect xylem element diameter. However, xylem element number decreased rapidly and in a quadratic manner for seedlings treated with increasing PEG-8000 concentrations (Figs. $3 \mathrm{D}, 6 \mathrm{~A}-\mathrm{D}$, and 7A-D). Nontreated salvia had approximately twice the xylem element number of PEG-treated salvia within a cross-section (4800 vs. 2600 xylem elements). For PEG-treated salvia, though, salvia treated with $15 \mathrm{~g} \cdot \mathrm{L}^{-1}$ of PEG- 8000 had only 200 more xylem elements than salvia treated with twice as much PEG. By comparison, drought-stressed apple cactus had narrow vessels, but vessel density (the number of vessels in $1 \mathrm{~mm}^{2}$ of axial wood) was not affected (Arnold and Mauseth, 1997).

For roots, there was a trend for xylem cross-sectional area to 

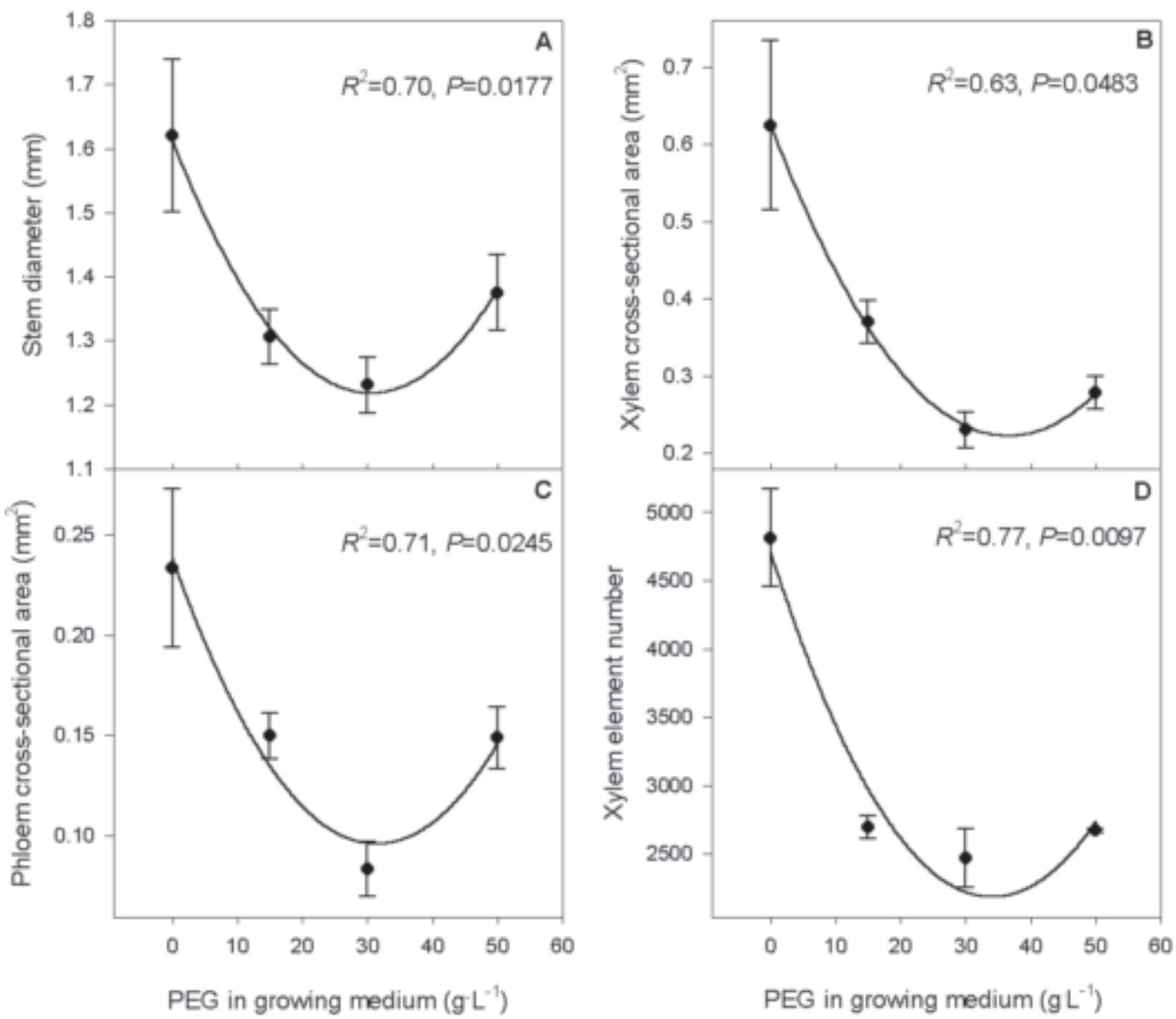

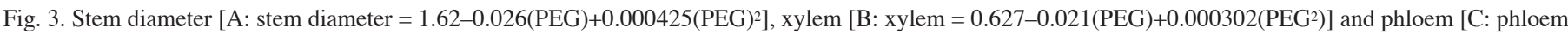

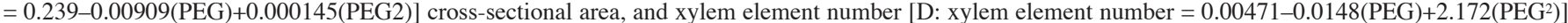

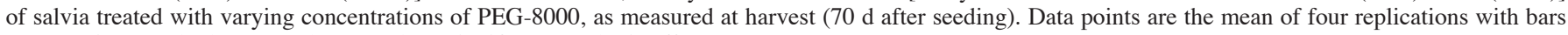
representing standard error, and curves show significant quadratic effects.

Table 1. The effects of PEG-8000 treatment of annual salvia on the ratio of phloem : stem, xylem : stem, and xylem : phloem crosssectional areas.

\begin{tabular}{lccc}
\hline Treatment & $r^{2}$ & $P$ & Regression equation \\
\hline Phloem : stem & & NS & \\
Xylem : stem & 0.52 & 0.0073 & $0.278-0.002$ (PEG) \\
Xylem : phloem & 0.41 & 0.0335 & $2.79-0.0127$ (PEG) \\
\hline
\end{tabular}

NsNonsignificant.

decrease with increasing PEG-8000 concentration in the growing medium (data not shown). However, this trend was not significant, and PEG-8000 did not affect the pith cross-sectional area in roots either. Root, stele, and cortex diameter of soybean [Glycine max (L.) Merr.] and peach [Prunus persica (L.) Batsch.] also were not affected by drought stress (Rieger and Litvin, 1999). With regard to elongation, roots are less sensitive to drought stress than shoots (Frensch, 1997). In this experiment, drought stress did not affect the anatomical root features examined. Controlled drought stress also did not affect whole leaf, palisade, or spongy mesophyll thicknesses (data not shown).

\section{Conclusions}

Additions of $15-50 \mathrm{~g} \cdot \mathrm{L}^{-1}$ of PEG-8000 to the growing medium reduced and delayed salvia germination. Drought-stressed salvia had reduced shoot and root elongation. Leaf $\Psi_{\mathrm{w}}$ and $\Psi_{\mathrm{p}}$ were lower for seedlings treated with PEG-8000, and reductions in leaf $\Psi_{\mathrm{w}}$ were significantly correlated with height reductions. Turgor potential is the driving force for cell elongation, so reduced $\Psi_{\mathrm{w}}$ and $\Psi_{\mathrm{p}}$ contributed to reduced elongation of annual salvia. Salvia also exhibited typical anatomical changes associated with mild drought stress. Seedlings treated with PEG-8000 had narrower stems due to an overall reduction in vascular tissues. Pith and cortex tissues were not significantly affected by controlled drought. Stem diameter could have simply been smaller because treated seedlings were smaller. However, xylem tissue appeared to decrease because of controlled drought, not only because salvia seedlings grown in PEG-8000 were smaller than nontreated salvia. Xylem tissue was reduced because there were fewer xylem elements, not smaller xylem element diameter in treated salvia as compared to nontreated salvia. It appears that PEG-8000 may be used as a replacement or supplement for chemical growth retardants in the commercial production of annual salvia. PEG appeared to reduce elongation mainly by reducing $\Psi_{\mathrm{w}}$ and $\Psi_{\mathrm{p}}$. However, reduced xylem development likely contributed to the observed morphological changes.

\section{Literature Cited}

Arnold, D.H. and J.D. Mauseth. 1997. Effects of environmental factors on development of wood. Amer. J. Bot. 86:367-371.

Burnett, S.E. 2004. Effects of polyethylene glycol on the morphology of ornamental seedlings. PhD Diss., Dept. Hort., Univ. of Georgia, Athens. 


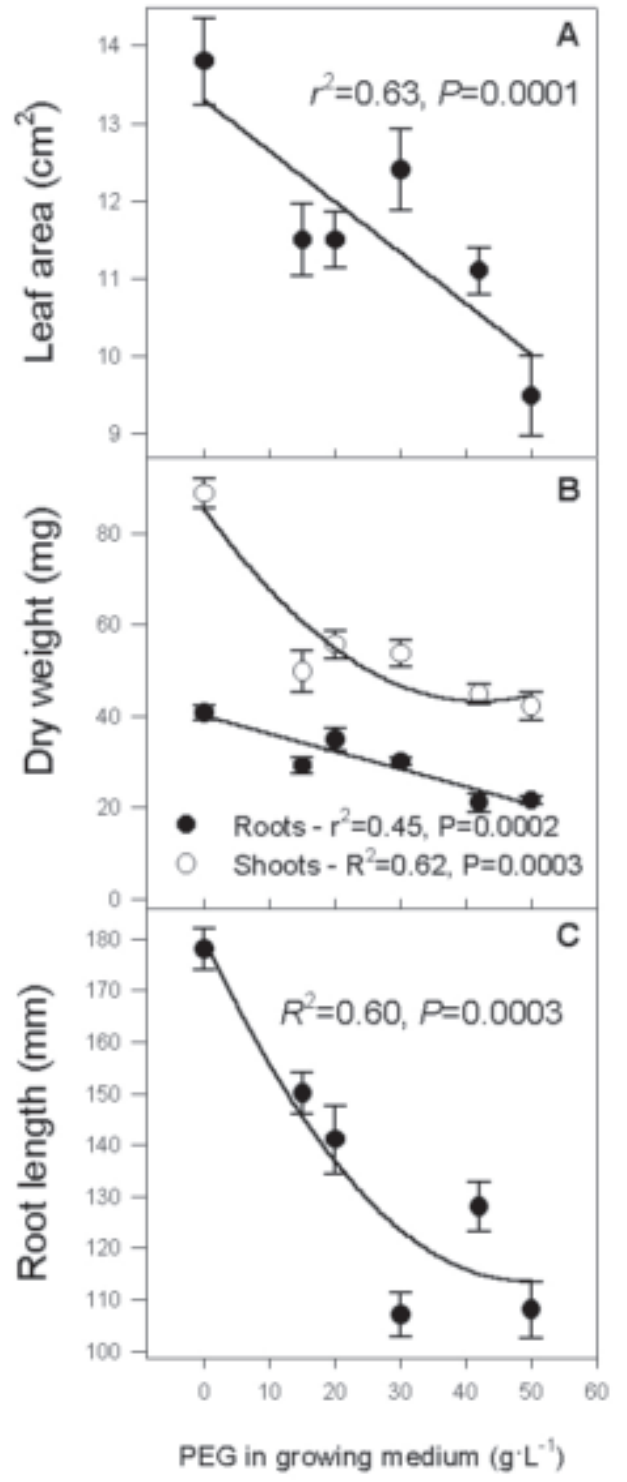

Fig. 4. The effects of PEG-8000 in the growing medium on leaf area [A: leaf area $=13.3-0.0654(\mathrm{PEG})]$, shoot and root dry weights [B: shoot dry weight $=$ 85.4-2(PEG) $+0.0237(\mathrm{PEG})^{2} ;$ root dry weight $\left.=40-0.386(\mathrm{PEG})\right]$, and root length $\left[\mathrm{C}\right.$ : root length $\left.=180-2.7(\mathrm{PEG})+0.0274(\mathrm{PEG})^{2}\right]$ per plant for salvia treated with PEG-8000 as measured at harvest ( $70 \mathrm{~d}$ after seeding). Data points are the mean of six replications with bars representing standard error, and curves show significant linear or quadratic effects.

Burnett, S.E., P.A. Thomas, and M.W. van Iersel. 2005. Postgermination drenches with PEG-8000 reduce growth of salvia and marigolds. HortScience 40:675-679.

Carpita, N. and M. McCann. 2000. The cell wall, p. 52-108. In: B.B. Buchanan, W. Gruissem, and R.L. Jones (eds.). Biochemistry and molecular biology of plants. Amer. Soc. Plant Physiol., Rockville, Md.

Choi, W., S. Kang, H. Park, S. Kim, K. Lee, K. Lee, H. Shin, and S. Choi. 2000. Effects of water stress by PEG on growth and physiological traits in rice seedlings. Korean J. Crop Sci. 45:112-117.

Cosgrove, D.J. 1997. Relaxation in a high-stress environment: The molecular bases of extensible cell walls and cell enlargement. Plant Cell 9:1031-1041.

Eakes, D.J., R.D. Wright, and J.R. Seiler. 1991. Moisture stress conditioning effects on Salvia splendens 'Bonfire'. J. Amer. Soc. Hort. Sci. 116:716-719.

Esau, K. 1977. Anatomy of seed plants, $2^{\text {nd }}$ ed. Wiley, New York.

Frensch, J. 1997. Primary responses of root and leaf elongation to

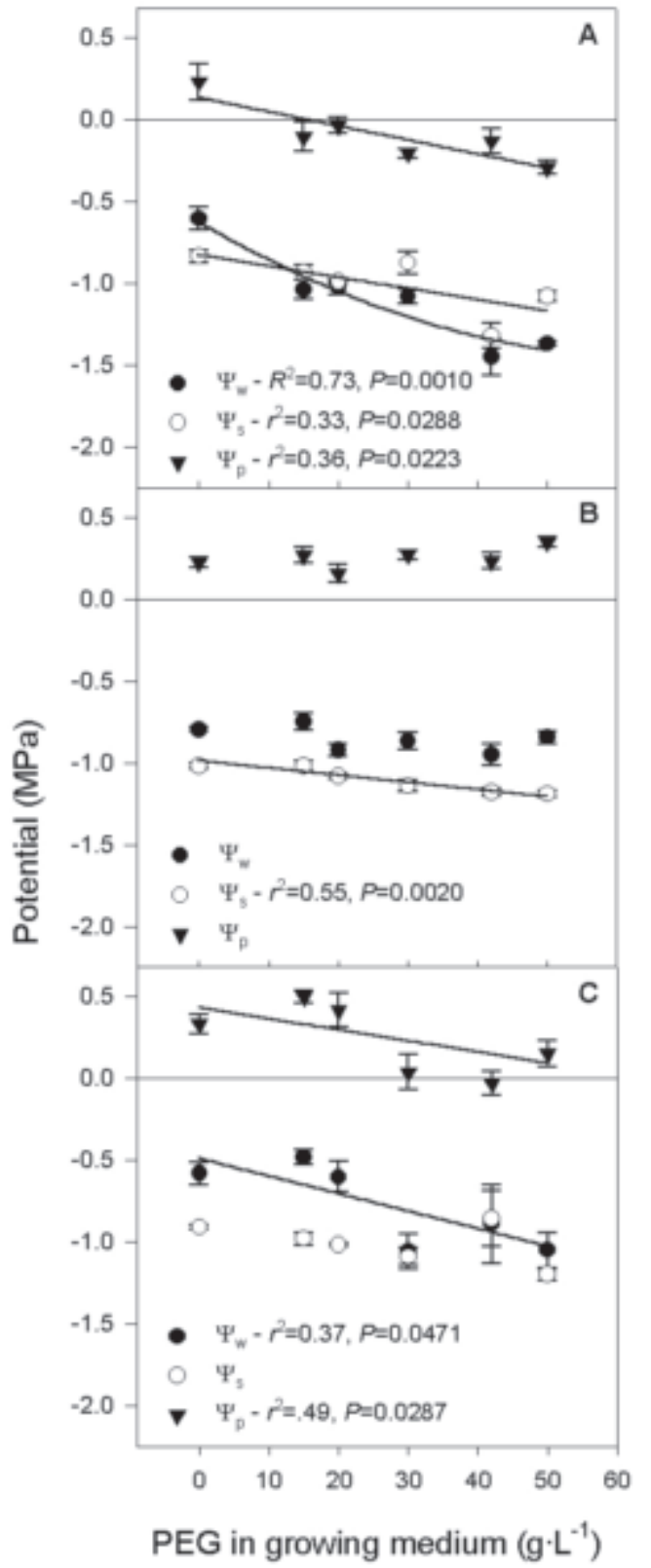

Fig. 5. Water, osmotic, and turgor potential of salvia leaves treated with varying concentrations of PEG-8000. Second acropetal pair of salvia leaves were measured midday. Data points are the mean of three replications with bars representing standard error, and curves show significant linear or quadratic effects. A: $\Psi_{\mathrm{w}}, \Psi_{\mathrm{s}}$, and $\Psi_{\mathrm{p}}, 21$ dafter seeding $\left[\Psi_{\mathrm{w}}=-0.626-0.0247(\mathrm{PEG})+0.00018(\mathrm{PEG})^{2}\right.$; $\left.\Psi_{\mathrm{s}}=-0.903-0.00507(\mathrm{PEG}) ; \Psi_{\mathrm{p}}=0.134-0.00861(\mathrm{PEG})\right] ; \mathrm{B}: \Psi_{\mathrm{w}}, \Psi_{\mathrm{s}}$, and $\Psi_{\mathrm{p}}$, $35 \mathrm{~d}$ after seeding $\left[\Psi_{\mathrm{s}}=-0.986-0.00439(\mathrm{PEG})\right] ; \mathrm{C}: \Psi_{\mathrm{w}}, \Psi_{\mathrm{s}}$, and $\Psi_{\mathrm{p}}, 56 \mathrm{~d}$ after seeding $\left[\Psi_{\mathrm{w}}=-0.49-0.0107(\mathrm{PEG}) ; \Psi_{\mathrm{p}}=0.43-0.00674(\mathrm{PEG})\right]$.

water deficits in the atmosphere and soil solution. J. Expt. Bot. 48:985-999.

Gill, P.K., A.D. Sharma, P. Singh, and S.S. Bhullar. 2001. Effect of various abiotic stresses on the growth, soluble sugars and water relations of sorghum seedlings grown in light and darkness. Bulgarian J. Plant Physiol. 27:72-84.

Hsiao, T.C. and J. Jing. 1987. Leaf and root expansive growth in response to water deficits. In: D.J. Cosgrove and D.P. Knievel (eds.). Physiology of cell expansion during plant growth, Amer. Soc. Plant Physiol., Rockville, Md.

Kjellander, R. and E. Florin. 1981. Water structure and changes in thermal stability of the system poly (ethylene oxide)-water. J. Chem. Soc., Faraday Trans. I. 77:2053-2077. 


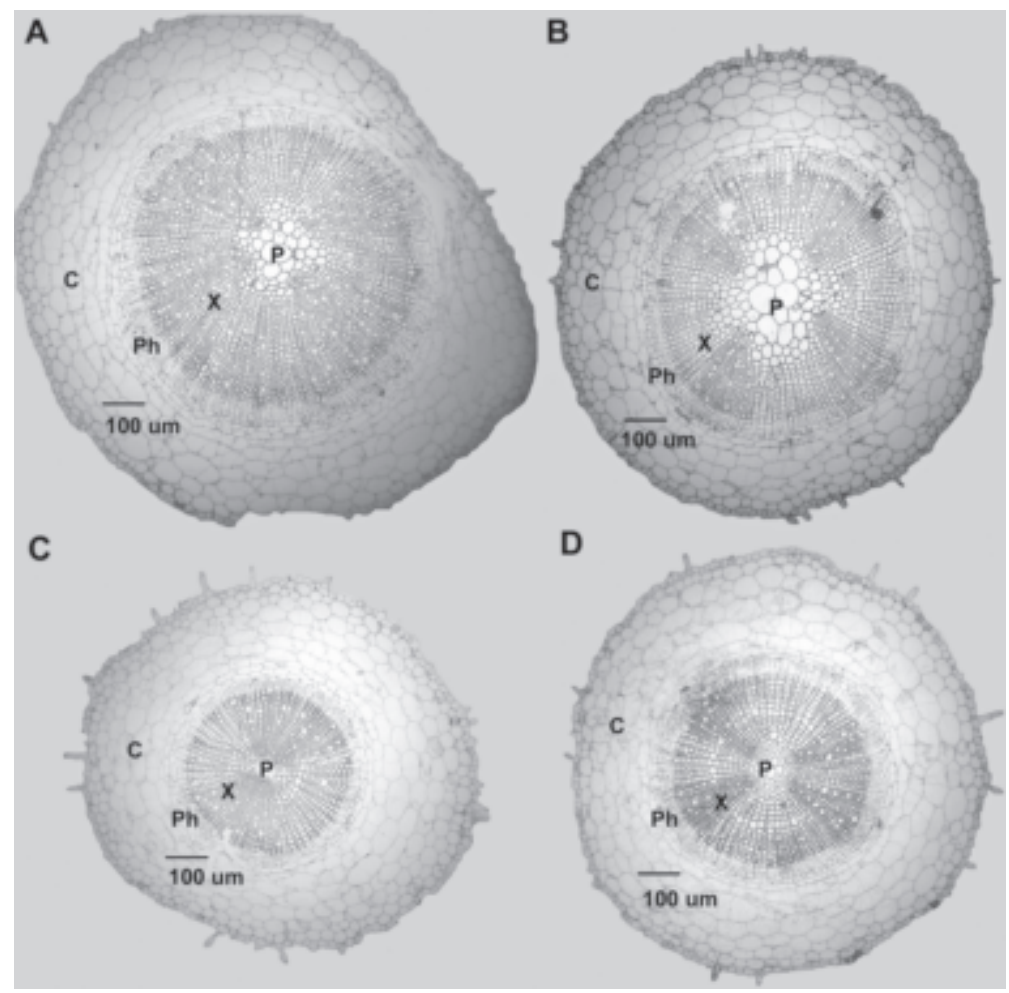

Fig. 6. Stem cross sections of entire stems from annual salvia treated with $0,15,30$, or 50 $\mathrm{g} \cdot \mathrm{L}^{-1}$ of PEG-8000. Figures are labeled as follows: $\mathrm{P}=$ pith, $\mathrm{X}=\mathrm{xylem}, \mathrm{Ph}=$ phloem, and $\mathrm{C}=$ cortex; $\mathrm{A}: 0 \mathrm{~g} \cdot \mathrm{L}^{-1}$; B: $15 \mathrm{~g} \cdot \mathrm{L}^{-1}$; C: $30 \mathrm{~g} \cdot \mathrm{L}^{-1} ; \mathrm{D}: 50 \mathrm{~g} \cdot \mathrm{L}^{-1}$ of PEG-8000.

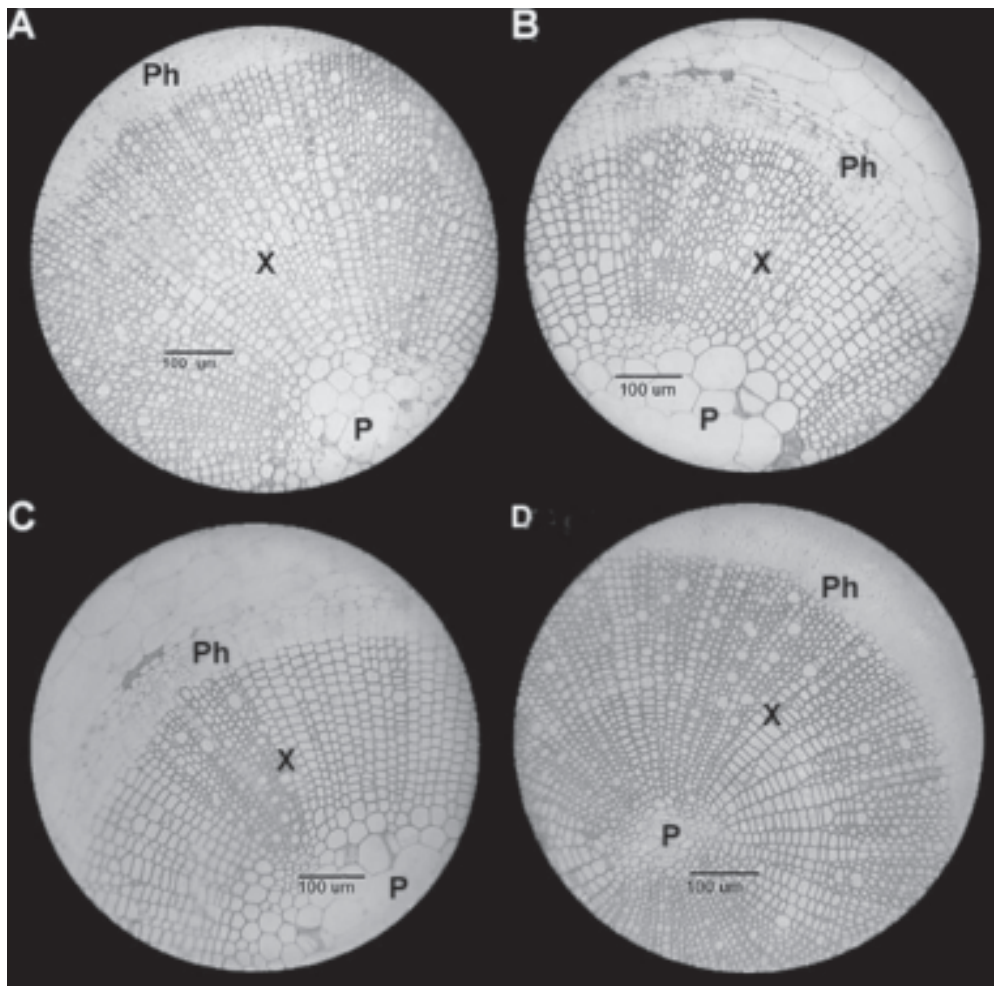

Fig. 7. Close-ups of stem cross sections from annual salvia treated with $0,15,30$, or 50 $\mathrm{g} \cdot \mathrm{L}^{-1}$ of PEG-8000. Figures are labeled as follows: $\mathrm{P}=$ pith, $\mathrm{X}=\mathrm{xylem}$, and $\mathrm{Ph}=$ phloem; A: $0 \mathrm{~g} \cdot \mathrm{L}^{-1} ; \mathrm{B}: 15 \mathrm{~g} \cdot \mathrm{L}^{-1}$; $: 30 \mathrm{~g} \cdot \mathrm{L}^{-1}$; D: $50 \mathrm{~g} \cdot \mathrm{L}^{-1}$ of PEG- 8000.
Latimer, J.G. 1992. Drought, paclobutrazol, abscisic acid, and gibberellic acid as alternatives to daminozide in tomato transplant production. J. Amer. Soc. Hort. Sci. 117:243-247.

Latimer, J.G. and R.F. Severson. 1997. Effect of mechanical and moisture-stress conditioning on growth and cuticle composition of broccoli transplants. J. Amer. Soc. Hort. Sci. 122:788-791.

Lawlor, D.W. 1970. Absorption of polyethylene glycols by plants and their effects on plant growth. New Phytol. 69:501-513.

Lescovar, D.I. and D.J. Cantliffe. 1992. Pepper seedling growth response to drought stress and exogenous abscisic acid. J. Amer. Soc. Hort. Sci. 117:389-393.

Lo Gullo, M.A., S. Salleo, E.C. Piaceri, and R. Rosso. 1995. Relations between vulnerability to xylem embolism and xylem conduit dimensions in young trees of Quercus cerris. Plant Cell Environ. 18:661-669.

Lovisolo, C. and A. Schubert. 1998. Effects of water stress on vessel size and xylem hydraulic conductivity in Vitis vinifera L. J. Expt. Bot. 49:693-700.

Metcalfe, C.R. and L. Chalk. 1957. Anatomy of the dicotyledons: Leaves, stem, and wood in relation to taxonomy with notes on economic uses, vol. II. Oxford Univ. Press, London.

Mohr, H. and P. Schopfer. 1995. Plant physiology. SpringerVerlag, Berlin, Germany.

Nau, J. 1998. Salvia, p. 730-733. In: V. Ball (ed.). Ball redbook, $16^{\text {th }}$ ed. Ball Publishing, Batavia, Ill.

Osório, J., M.L. Osório, M.M. Chaves, and J.S. Pereira. 1998. Water deficits are more important in delaying growth than in changing patterns of carbon allocation in Eucalyptus globulus. Tree Physiol. 18:363-373.

Penfound, W.T. 1931. Plant anatomy as conditioned by light intensity and soil moisture. Amer. J. Bot. 18:558-572.

Rieger, M. and P. Litvin. 1999. Root system hydraulic conductivity in species with contrasting root anatomy. J. Expt. Bot. 50:201-209.

Sharp, R.E. and W.J. Davies. 1979. Solute regulation and growth by roots and shoots of water-stressed maize plants. Planta 147:43-49.

Spurr, A.R. 1969. A low-viscosity epoxy resin embedding medium for electron microscopy. J. Ultrastructure Res. 26:31-43.

Steuter,A.A.,A. Mozafar, and J.R. Goodin. 1981. Water potential of aqueous polyethylene glycol. Plant Physiol. 67:64-67.

van Iersel, M.W. and K.S. Nemali. 2004. Drought stress can produce small, but not compact marigolds. HortScience 39:1298-1301.

van Volkenburgh, E. 1999. Leaf expansion-An integrating plant behavior. Plant, Cell Environ. 22:1463-1473.

Watts, S., J.L. Rodriguez, S.E. Evans, and W.J. Davies. 1981. Root and shoot growth of plants treated with abscisic acid. Ann. Bot. 47:595-602.

Zimmerman, M.H. 1983. Xylem structure and the ascent of sap. Springer-Verlag, Berlin, Germany.

Zou, C., R. Sands, and O. Sun. 2000. Physiological responses of radiata pine roots to soil strength and soil water deficit. Tree Physiol. 20:1205-1207. 